\title{
IPSS Risk Category
}

National Cancer Institute

\section{Source}

National Cancer Institute. IPSS Risk Category. NCI Thesaurus. Code C139296.

The risk categ ory for myelodysplastic syndrome progression that is derived from IPSS risk score. 